\title{
REALIZĂRI ŞI PERSPECTIVE LA PROGRAMUL DE CREARE A HIBRIZILOR DE PORUMB TIMPURIU
}

\author{
Borozan P., Musteaţa S., Spînu V. \\ Institutul de Fitotehnie „Porumbeni”, R. Moldova.e-mail-pantelimon.borozan@yahoo.com
}

\begin{abstract}
The article presents results of maize improvement for northern zones during activity from the year of fondation of the laboratory. Use of created original inbred lines have permited to develop 23 registered hybrids, including eight in Belarus, two in Rusia and two in Moldova. They also performs research on assessing the combining ability capacity, cold tolerance, height plant density and tolerance for main diseases of inbred lines. They have been created 38 early hybrids with maturity index FAO 160-310 and more than 85 inbred lines from different germplasm groups.
\end{abstract}

Key words: Grain yield, Hybrids, Inbred lines, Initial material, Maturity groups, Maize.

\section{Introducere}

Rezultatele obţinute în procesul de ameliorare în cadrul programelor de creare a hibrizilor și perfecționarea tehnologiilor de cultivare au sporit semnificativ producția de boabe la porumb. Programul de ameliorare a porumbului timpuriu destinat cultivării în zonele nordice cu regim termic limitat a fost iniţiat în anul 1974 şi dezvoltat după 1982 şi are o istorie relativ mai scurtă comparativ cu grupa de maturitate semitimpurie - semitardivă. Acest program de cercetare, este realizat în cadrul laboratorului de ameliorare a porumbului pentru zonele nordice, care pe parcursul activităţii s-au creat şi transferat în testările oficiale peste 38 hibrizi, dintre care 23 au fost omologaţi. Remarcăm că şi la compartimentul creării liniilor consangvinizate la etapa actuală, au fost obţinute rezultate semnificative în direcţia rezistenței tulpinilor la frângere și cădere. În procesul de ameliorare un progres semnificativ se semnalează în grupele de germoplasmă Reid Iodent și BSSS-B37 la valorile relative ale capacității generale și specifice de combinare [1]. În perioada de activitate a laboratorului s-au produs modificări radicale a materialului iniţial şi a surselor de germoplasmă, incluse în procesul de creare a liniilor consangvinizate. La prima etapă de ameliorare principalele surse de material iniţial erau hibrizii comerciali și experimentali de origine străină. Ulterior în procesul de sintetizare a materialului iniţial s-au folosit diferite tipuri de hibrizi sintetizaţi cu un scop bine determinat, populații sintetice cu bază genetică largă şi îngustă cu cota majorată a unei linii consangvinizate elită.

\section{Materiale şi metode}

În prezent principalele surse de material biologic iniţial sunt hibrizii simpli și încrucișările înrudite, create cu liniilor consangvinizate selectate în baza rezultatelor referitoare la capacitatea generală de combinare și a gradului de rudenie genetică. Încrucișările regresive se folosesc la îmbunătățirea liniilor consangvinizate, componente a hibrizilor din producere. Menționăm că în lucrările de selecție sunt incluse peste 85 linii şi familii omogenizate din generaţiile de consangvinizare $\mathrm{S}_{4}-\mathrm{S}_{6}$. Cu o frecvență mai înaltă în materialul iniţial sunt utilizate liniile din grupele de germoplasmă Iodent şi BSSS-B37. Colecția operațională a liniilor consangvinizate originale, au fost divizate în 5 grupe de germoplasmă cu următoarele cote a mostrelor: Reid Iodent - 35\%, Euroflint $-20 \%$, Dent timpuriu - 12\%, BSSS-B37 - 18\% și Lancaster - 8\%. Celelalte 7\% reprezintă linii cu diferită perioadă de maturitate, care au genealogie necunoscută. În ultimii ani la sintetizarea materialului inițial se includ donatori tardivi cu performanțe la producția de boabe și capacitate înaltă de combinare. Datorită utilizării a celor mai buni donatori de gene favorabile, în procesul de creare a 
materialului iniţial s-a redus numărul de genotipuri $\mathrm{F}_{1}$ și s-a majorat cantitatea plantelor în populații segregante $\mathrm{F}_{2}$ supuse autopolenizărilor.

\section{Rezultate şi discuţii}

Menționăm, că la prima etapă, o cotă majoră a exportului de seminţe reveneau hibrizilor Moldavskii 330MRf, Moldavskii 215MRf, Moldavskii 257CRf, creaţi până în anul 1982 [2]. Odată cu crearea laboratorului nominalizat, din 1982 ca obiect de studiu a devenit crearea hibrizilor de porumb cu maturitatea FAO 150-300, orientat spre crearea hibrizilor de tip dublu (A x B) x (C x D) și triliniari (A x B) x C cu producerea semințelor în baza androsterilității citoplasmatice și restaurării complete a fertilității polenului. (tab.1) În perioada respectivă, s-au creat hibrizii Porumbeni 176MRf, Bemo 181CRf, Bemo 182CRf, Bemo 172CRf și Nemo 216CRf. Popularitatea acestor hibrizi în Rusia, Belarus, Kazahstan, Ucraina și alte țări, se datora performanțelor agronomice, tehnologice și rentabilităţii producerii semințelor, inclusiv a gradului înalt de androsterilitate citoplasmatică la formele materne.

Tabelul 1 Caracteristica generală a unor hibrizi de porumb timpurii, înregistraţi în Catalogul Soiurilor de Plante.

\begin{tabular}{|c|c|c|c|c|c|}
\hline $\begin{array}{l}\mathrm{Nr} \\
\mathrm{d} / \mathrm{o}\end{array}$ & $\begin{array}{l}\text { Denumirea } \\
\text { hibridului }\end{array}$ & $\begin{array}{l}\text { Tipul de } \\
\text { încrucişări }\end{array}$ & $\begin{array}{c}\text { Grupa de } \\
\text { maturitate, } \\
\text { FAO }\end{array}$ & $\begin{array}{c}\text { Anul } \\
\text { înregistrării }\end{array}$ & Ţara \\
\hline 1. & Bemo 181CRf & $(\mathrm{AxB}) \times \mathrm{C}$ & 210 & 1988 & Belarus, Rusia \\
\hline 2. & Bemo 182CRf & $\begin{array}{l}(\mathrm{AxB}) \mathrm{x} \\
(\mathrm{CxD})\end{array}$ & 210 & 1995 & Belarus, Rusia \\
\hline 3. & Bermold 184CRf & $\begin{array}{l}(\mathrm{AxB}) \mathrm{x} \\
(\mathrm{CxD})\end{array}$ & 210 & 1994 & Belarus \\
\hline 4. & Bemo 160MRf & $(\mathrm{AxB}) \times \mathrm{C}$ & 160 & 1995 & Belarus \\
\hline 5. & Bemo 210CRf & $(\mathrm{AxB}) \times \mathrm{C}$ & 210 & 1995 & Belarus, Ucraina \\
\hline 6. & Bemo 201CRf & $(\mathrm{AxB}) \times \mathrm{C}$ & 210 & 1999 & Rusia \\
\hline 7. & Porumbeni 171CRf & $(\mathrm{AxB}) \times \mathrm{C}$ & 170 & 1997 & Rusia \\
\hline 8. & Bemo 172CRf & $(\mathrm{AxB}) \times \mathrm{C}$ & 170 & 1999 & 1993 \\
\hline 9. & Porumbeni 212CRf & $(\mathrm{AxB}) \times \mathrm{C}$ & 220 & 2001 & Belarus, Rusia \\
\hline 10. & Porumbeni 174CRf & $(\mathrm{AxB}) \times \mathrm{C}$ & 170 & 2003 & Belarus \\
\hline 11. & Porumbeni 175CRf & $\begin{array}{l}(\mathrm{AxB}) \mathrm{x} \\
(\mathrm{CxD})\end{array}$ & 180 & 2004 & Belarus \\
\hline 12. & Porumbeni 176MRf & $(\mathrm{AxB}) \times \mathrm{C}$ & 180 & 2006 & Belarus \\
\hline 13. & Rosmold 159CRf & $(\mathrm{AxB}) \times \mathrm{C}$ & 160 & 2012 & Rusia \\
\hline 14. & Rosmold 202MRf & $\left(\mathrm{A} \times \mathrm{A}_{1}\right) \times \mathrm{B}$ & 200 & 2012 & Rusia \\
\hline 15. & Bemo 235 & $\mathrm{~A} \times \mathrm{B}$ & 230 & 2014 & Belarus \\
\hline 16. & Bemo 203 & $(\mathrm{AxB}) \times \mathrm{C}$ & 210 & 2015 & Belarus \\
\hline 17. & Porumbeni 310 & $\mathrm{~A} \times \mathrm{B}$ & 310 & 2015 & Moldova, România \\
\hline 18. & Alimentar 325 & $\mathrm{~A} \times \mathrm{B}$ & 330 & 2015 & Moldova \\
\hline 19. & Porumbeni 220 & $\mathrm{~A} \times \mathrm{B}$ & 220 & 2017 & Belarus \\
\hline 20. & Porumbeni 243 & $\mathrm{~A} \times \mathrm{B}$ & 240 & 2017 & Belarus \\
\hline 21. & Porumbeni 305 & $\mathrm{~A} \times \mathrm{B}$ & 300 & 2017 & Moldova \\
\hline 22. & Porumbeni 230 & $\mathrm{~A} \times \mathrm{B}$ & 230 & 2018 & Belarus \\
\hline 23. & Porumbeni 221 & $\left(\mathrm{~A} \times \mathrm{A}_{1}\right) \times \mathrm{B}$ & 220 & 2019 & Belarus \\
\hline
\end{tabular}


Schimbările şi cerinţele pe piața de realizare a semințelor de porumb în ultimii ani au schimbat orientarea ameliorării spre hibrizii simpli A x B și simpli modificați $\left(\mathrm{A} \times \mathrm{A}_{1}\right) \times \mathrm{B}$. Promovarea cu prioritate a hibrizilor simpli în grupa de maturitate timpurie (FAO 220 - 280) se datorează performanțelor deosebite după producție, rezistență la frângerea tulpinilor și căderea radiculară, uniformităţii plantelor, aspectul comercial precum şi a reacției la tehnologiile noi de cultivare, densități sporite a plantelor, creșterea dozelor de azot, recoltarea mecanizată în boabe. Menționăm că, din 11 hibrizi FAO 160 - 310 omologaţi în anii 2012 2019 în catalogul soiurilor de plante din Rusia, Belarus și Moldova, 7 sunt simpli, 2 - simpli modificați și 2 de tip triliniar. Majoritatea acestor hibrizi au formule de multiplicare în baza androsterilității citoplasmatice de tip M(S) și doar Rosmold 159CRf, producerea de semințe se bazează pe tipul C de androsterilitate [1].

Crearea hibrizilor experimentali se efectuează manual prin încrucişări în scheme speciale de tip topcross. In procesul de creare a hibrizilor timpurii se utilizează formulele de încrucișări a formelor parentale în modele heterotice Euroflint x Dent Canadian, Reid Iodent x Euroflint și Reid Iodent x BSSS-B37. Primele două formule de hibridare a porumbului, au fost realizate într-o perioadă mai lungă, pe când ultima, din convarietatea dentiformis, a fost folosită în ultimii ani şi în premieră primul hibrid simplu, fiind Bemo 235, omologat în Belarus (2014) și Porumbeni 310 în Moldova (2015). Ultimii hibrizi simpli (Porumbeni 220, Porumbeni 221, Porumbeni 230, Porumbeni 243 și Porumbeni 305) înscrişi în catalogul soiurilor de plante în perioada 2017-2019, de asemenea sunt dezvoltaţi în modelul heterotic Reid Iodent x BSSS-B37. Menţionăm, că până la omologarea hibrizilor nominalizaţi pe parcursul anilor 2005-2015, anual se experimentau 2000 hibrizi în culturi comparative de orientare și 500 în preconcurs cu un volum total de 5500 parcele de $10 \mathrm{mp}^{2}$. Paralel în culturi comparative de concurs se testau 50-60, iar în 2 localităţi ecologice experimentările se efectuau asupra 25-30 combinaţii hibride. Actual se testează 1500 combinaţii hibride în culturi comparative de orientare, 200 în preconcurs, 40-50 concurs și 1 localitate în ecologice, care permite doar parțial evaluarea hibrizilor în special a adaptării la diverse condiții climaterice din zonele de omologare. Prin urmare, lărgirea rețelei ecologice după anul doi de experimentare ar fi o soluție în scopul accelerării procesului de evidențiere veridică a hibrizilor competitivi pentru transfer în testări oficiale de stat.

Analiza rezultatelor experimentării liniilor consangvinizate utilizate ca forme parentale în culturi comparative de orientare pe parcursul a mai multor ani relevă tendința de creștere a producției și majorarea mostrelor cu pierderea rapidă a umidității boabelor după maturitatea fiziologică. În medie pe anii 2017 - 2019 liniile consangvinizate cu germoplasmă Reid Iodent din colecția operațională au realizat producție medie de 3,7 t/ha cu o variație a genotipurilor în intervalul 2,78 - 4,93 t/ha boabe.

Producția de 4,24 - 6,45 t/ha au fost înregistrate în anul $2017 \mathrm{cu}$ condiții suficient de favorabile pentru cultura porumbului. Pentru comparație remarcăm faptul că liniile cu germoplasma BSSS-B37 au format recolta medie de 3,89 t/ha iar mostrele grupei Euroflint 3,03 t/ha. Sporul producției formelor parentale per se, considerat ca câștig în producerea de semințe, are o anumită influență pozitivă asupra capacității de producție a combinațiilor hibride. Selecția fenotipică a caracterelor agronomice valoroase și promovarea descendențelor productive și cu conținut înalt de substanță uscată în boabe rezultă cu evidențierea unui volum mai restrâns de familii performante. De asemenea s-a atins o îmbunătăţire esenţială a precocității în grupa Dent timpuriu corelată cu producția de boabe rezonabilă pentru mostrele ultratimpurii. 
Tabelul 2. Rezultatele liniilor consangvinizate utilizate în hibrizii timpurii (media 2017 - 2019)

\begin{tabular}{|c|c|c|c|c|c|c|c|c|}
\hline \multirow[t]{2}{*}{ Pedigreul } & \multirow{2}{*}{$\begin{array}{l}\text { Ritm } \\
\text { de } \\
\text { creşter } \\
\text { e }\end{array}$} & \multicolumn{2}{|c|}{$\begin{array}{c}\text { Zile de la } \\
\text { răsărit până la }\end{array}$} & \multirow{2}{*}{$\begin{array}{c}\text { Talia } \\
\text { plantei } \\
\text {, cm }\end{array}$} & \multirow{2}{*}{$\begin{array}{l}\text { Inserţia } \\
\text { ştiulete } \\
\text {-lui, cm }\end{array}$} & \multirow{2}{*}{$\begin{array}{l}\text { Umidi } \\
\text {-tatea } \\
\text { boabe- } \\
\text { lor, \% }\end{array}$} & \multirow{2}{*}{$\begin{array}{c}\text { Producţi } \\
\text { a de } \\
\text { boabe, } \\
\text { t/ha }\end{array}$} & \multirow{2}{*}{$\begin{array}{l}\text { Indice } \\
\text { de } \\
\text { selecţi } \\
\text { e }\end{array}$} \\
\hline & & $\begin{array}{c}\text { mătăsi } \\
\text { t }\end{array}$ & $\begin{array}{c}\text { matu } \\
- \\
\text { rizare }\end{array}$ & & & & & \\
\hline AN615/95MRf & 8,0 & 54,0 & 100,0 & 135,0 & 35,0 & 12,9 & 2,70 & 2,35 \\
\hline MKP20cmsC & 7,0 & 58,0 & 109,0 & 135,0 & 42,5 & 13,4 & 2,54 & 2,19 \\
\hline MKP22MRf & 6,8 & 62,5 & 101,0 & 167,5 & 60,0 & 12,7 & 3,40 & 2,96 \\
\hline MKP27 & 7,3 & 62,5 & 103,0 & 210,0 & 70,0 & 13,2 & 2,86 & 2,48 \\
\hline MKP23 & 7,5 & 54,0 & 102,0 & 152,5 & 47,5 & 12,8 & 2,92 & 2,54 \\
\hline MKP29 & 7,5 & 61,5 & 109,0 & 177,5 & 77,5 & 12,8 & 3,77 & 3,28 \\
\hline $\begin{array}{l}\text { MKP52Acms } \\
\text { M }\end{array}$ & 7,0 & 57,0 & 102,0 & 137,5 & 42,5 & 13,4 & 2,37 & 2,05 \\
\hline MKP42 & 7,5 & 59,5 & 104,0 & 137,5 & 42,5 & 12,8 & 2,37 & 2,06 \\
\hline MKP71cmsM & 7,3 & 62,0 & 105,0 & 175,0 & 55,0 & 12,7 & 4,22 & 3,68 \\
\hline MKP71MRf & 7,0 & 61,5 & 104,0 & 177,5 & 67,5 & 12,6 & 3,63 & 3,17 \\
\hline AN1262/16 & 6,5 & 61,0 & 102,0 & 162,5 & 62,5 & 12,9 & 3,20 & 2,78 \\
\hline AN1269/16 & 7,3 & 56,0 & 104,0 & 162,5 & 55,0 & 13,1 & 4,61 & 4,00 \\
\hline MKP70MRf & 7,0 & 62,5 & 105,0 & 180,0 & 55,0 & 12,4 & 3,83 & 3,35 \\
\hline MKP60cmsM & 7,3 & 58,5 & 102,0 & 155,0 & 57,5 & 12,6 & 4,22 & 3,68 \\
\hline MKP61cmsM & 7,5 & 59,5 & 101,0 & 162,5 & 50,0 & 12,4 & 4,06 & 3,55 \\
\hline MKP601cmsM & 7,0 & 59,0 & 108,0 & 155,0 & 55,0 & 13,4 & 4,09 & 3,54 \\
\hline MKР602 & 7,0 & 61,5 & 108,0 & 150,0 & 50,0 & 12,6 & 2,78 & 2,34 \\
\hline MKP611 & 7,3 & 63,0 & 102,0 & 147,5 & 55,0 & 11,9 & 2,86 & 2,51 \\
\hline MKP612 & 7,5 & 64,0 & 108,0 & 167,5 & 55,0 & 12,4 & 4,01 & 3,51 \\
\hline MKP64cmsM & 7,0 & 63,0 & 106,0 & 155,0 & 52,5 & 10,5 & 4,21 & 3,76 \\
\hline MKP63cmsM & 8,0 & 65,0 & 102,0 & 185,0 & 65,0 & 12,4 & 4,93 & 4,31 \\
\hline AN988/15 & 7,8 & 64,5 & 108,0 & 217,5 & 67,5 & 12,8 & 4,64 & 4,04 \\
\hline
\end{tabular}

La compartimentul creareării liniilor consangvinizate persistă anumite carențe la gradul de toleranță la tăciunele comun (Ustilago Maydis) și prăfos (Sorosporium raileanum) la materialul biologic cu germoplasma BSSS-B37. Descendențele cu bob indurata a germoplasmei Euroflint, deși posedă toleranță înaltă la temperaturile suboptimale, manifestă o slabă adaptare la condițiile secetelor de sol și atmosferice. Această particularitate în anii nefavorabili pentru cultura porumbului timpuriu are expresie drastică la descendențele din generațiile avansate de inbreding cu grad înalt de homozigoție. Selecția fenotipică între descendenți cu origine din diferiți genitori este preponderent orientată la producția de boabe realizată, umiditatea boabelor la recoltare și capacitatea generală de combinare [3]. La selectarea și evaluarea liniilor consangvinizate o atenție sporită este acordată selecției fenotipice între descendențele $S_{1}-S_{5}$ după principalii indici ameliorativi. În prezent, testarea capacității de combinare se efectuează în generațiile avansate de consangvinizare $\left(\mathrm{S}_{4}-\mathrm{S}_{5}\right)$, care rezultă cu selectarea liniilor înzestrate cu capacitate de producție înaltă în combinații hibride și per se. Datele din literatură, publicate în ultima perioadă, indică că valoarea liniilor consangvinizate per se joacă un rol important în ameliorarea performanțelor de heterozis și 
nonheterotice, inclusiv producția, pretabilitatea la recoltarea mecanizată, toleranța la densități înalte a plantelor și la factorii abiotici nefavorabili [4].

\section{Concluzii}

1) Analiza rezultatelor la crearea liniilor consangvinizate constată faptul, că evidențierea descendențelor fenotipic cu capacitate înaltă de combinare, îmbinată cu alte caractere și însușiri agronomice valoroase, este un proces dificil cu o probabilitate destul de joasă. În toată perioada de activitate a laboratorului au fost incluse peste 200 linii consangvinizate originale, utilizate ca forme parentale ale hibrizilor testaţi în culturi comparative de concurs, dintre care numai 30 mostre s-au realizat ca forme parentale în hibrizi omologați și transferați pentru testări oficiale de stat.

2) Brevete pentru soi de plantă au fost obținute la 9 linii, iar 3 se află în procedura de expertizare tehnică la AGEPI.

3) În final concluzionăm că programul de ameliorare a porumbului pentru export în zonele nordice a realizat o colecție bogată de linii originale și hibrizi omologați în diferite țări, care au ocupat suprafețe esențiale de cultivare. Pe parcursul perioadei de activitate științifică au fost perfecționate unele elemente metodologice de ameliorare, relatate în multiple publicații.

\section{Bibliografie}

1. Borozan Pantelimon, Musteața Simion, Rusu Ghenadie. Rezultate și perspective în ameliorarea porumbului timpuriu. Materialele conferinței internaţionale consacrate jubileului de 40 ani de la data fondării. Pașcani, 17 septembrie 2014, p. 13-26.

2. Micu V.E. Activitatea instituțiilor de cercetare de profil agrar în condițiile economiei de piață. În "Rezultatele și perspectivele cercetărilor la cultura plantelor de câmp în Republica Moldova", Chișinău, 2014, p. 114- 121.

3. Мустяца С. И., Борозан П.А., Брума С.Г., Русу Г.В. Создание, оценка, классификация и использование самоопыленных линий скороспелой кукурузы. Materialele conferinţei internaţionale consacrate jubileului de 40 ani de la data fondării. Paşcani, 17 septembrie 2014, p. 70-98.

4. Haș Ioan. Heterozisul la porumb. În "Porumbul. Studiu monografic", București, 2004, p. $311-362$. 